\title{
Synthesis and Crystal Structure of the New Telluric Acid Adduct $(\mathrm{RbCl})_{3} \cdot \mathrm{Te}(\mathrm{OH})_{6}$
}

\author{
Dirk Mahlmeister and Elisabeth Irran \\ Institut für Chemie, Technische Universität Berlin, Straße des 17. Juni 135, 10623 Berlin, Germany \\ Reprint requests to Dr. Elisabeth Irran. Fax: +49 30314 79656. E-mail: elisabeth.irran@tu-berlin.de
}

Z. Naturforsch. 2012, 67b, 1-4; received October 17, 2011

\begin{abstract}
The new telluric acid adduct $(\mathrm{RbCl})_{3} \cdot \mathrm{Te}(\mathrm{OH})_{6}$ was prepared by dissolving $\mathrm{RbCl}$ and $\mathrm{Te}(\mathrm{OH})_{6}$ in the molar ratio of $3: 1$ in deionized water at r.t. and slow evaporation of the solvent in air. The crystal structure of the colorless crystals was determined with single-crystal X-ray diffraction (trigonal space group: $R \overline{3} c$ (no. 167), $a=14.4392(8), c=10.4301(16) \AA, Z=6)$. In $(\mathrm{RbCl})_{3} \cdot \mathrm{Te}(\mathrm{OH})_{6}$, the rubidium atom is surrounded by five chlorine and four oxygen atoms in form of an irregular tricapped trigonal prism. Each tellurium atom is octahedrally surrounded by six oxygen atoms. The $\mathrm{Te}(\mathrm{OH})_{6}$ octahedra and the $\mathrm{RbCl}_{5} \mathrm{O}_{4}$ polyhedra are linked to a dense three-dimensional network which is additionally strengthened by hydrogen bonds.
\end{abstract}

Key words: Rubidium Chloride, Telluric Acid, Crystal Structure

\section{Introduction}

In the group of solids formed from telluric acid and alkali halides the compounds $\mathrm{NaF} \cdot \mathrm{Te}(\mathrm{OH})_{6}[1]$, $(\mathrm{KF})_{2} \cdot \mathrm{Te}(\mathrm{OH})_{6}[2],(\mathrm{CsF})_{2} \cdot \mathrm{Te}(\mathrm{OH})_{6} \cdot 2 \mathrm{H}_{2} \mathrm{O}[3]$, and $(\mathrm{CsCl})_{2} \cdot \mathrm{Te}(\mathrm{OH})_{6}$ [4] are known. In these salts the $\mathrm{OH}$ groups of the $\mathrm{Te}(\mathrm{OH})_{6}$ octahedra are involved in $\mathrm{O}-\mathrm{H} \cdots X(X=\mathrm{F}, \mathrm{Cl})$ hydrogen bonds. The aim of the present systematic investigation of adducts between telluric acid and further halides was to find new compounds with interesting properties like proton conductivity or ferroelectricity.

\section{Experimental Section}

$\mathrm{Te}(\mathrm{OH})_{6}$ (Aldrich, $97.5-102.5 \%$ ) was mixed with $\mathrm{NaCl}$, $\mathrm{NaBr}, \mathrm{NaI}, \mathrm{KCl}, \mathrm{KBr}, \mathrm{KI}, \mathrm{NH}_{4} \mathrm{Cl}, \mathrm{NH}_{4} \mathrm{Br}$, or $\mathrm{RbCl}$ in the molar ratios halide to telluric acid of $1: 1,2: 1,3: 1$, and $4: 1$. The mixtures were dissolved in deionized water at r.t., and the solvent was allowed to evaporate. The powders or crystals thus obtained were ground and investigated with a Bruker AXS D5000 powder diffractometer (monochromatized $\mathrm{Cu} K_{\alpha 1}$ radiation) in order to check if new adducts had been formed or if just the educts had crystallized separately. As all compounds were water soluble, the powders were fixed with grease on a flat silicon sample holder.

Unfortunately, from all mixtures containing $\mathrm{NaCl}, \mathrm{NaBr}$, $\mathrm{KCl}, \mathrm{KBr}, \mathrm{NH}_{4} \mathrm{Cl}$, or $\mathrm{NH}_{4} \mathrm{Br}$ the educts crystallized separately. Upon mixing $\mathrm{NaI}$ or $\mathrm{KI}$ with $\mathrm{Te}(\mathrm{OH})_{6}$, redox reactions were observed with formation of iodine. The products of these reactions were not investigated in detail.
In the mixtures of $\mathrm{Te}(\mathrm{OH})_{6}$ with rubidium chloride a new compound was detected. In powder X-ray diffraction measurements it was observed that only the sample from the $3: 1$ mixture $(\mathrm{pH}=6)$ was a single phase. Therefore we assumed the formula $(\mathrm{RbCl})_{3} \cdot \mathrm{Te}(\mathrm{OH})_{6}$ for this new compound which crystallizes in colorless blocks.

Data for the single-crystal structure determination of $(\mathrm{RbCl})_{3} \cdot \mathrm{Te}(\mathrm{OH})_{6}$ (Tables 1 and 2 ) were collected on an Oxford-Diffraction Xcalibur diffractometer, equipped with a Sapphire S CCD area detector and a graphite monochromator utilizing $\operatorname{Mo} K_{\alpha}$ radiation $(\lambda=0.71073 \AA)$. Suitable crystals were attached to glass fibers using perfluoropolyalkylether oil (ABCR) and transferred to a goniostat where they were cooled to $150 \mathrm{~K}$ for data collection. Software packages used: CRYSALIS CCD for data collection, CRYSALIS RED for cell refinement and data reduction [5].

The unit cell was found to be trigonal, with the lattice parameters $a=14.4392(8)$ and $c=10.4301$ (16) $\AA$ (hexagonal setting). From systematic absences the space groups $R 3 c$ and $R \overline{3} c$ were possible, and $R \overline{3} c$ (no. 167) was confirmed by the successful solution of the structure.

The crystal structure was solved by Direct Methods and refined on $F^{2}$ using full-matrix least-squares (SHELXS/L97 [6]). The position of the $\mathrm{H}$ atom was found in the electron density map and was refined with a restrained $\mathrm{O}-\mathrm{H}$ distance. It was necessary to apply a numeric absorption correction of the intensities to achieve reasonable displacement parameters because of the presence of the heavy atoms $\mathrm{Te}$ and $\mathrm{Rb}$ in the crystal [5].

Further details of the crystal structure investigation may be obtained from Fachinformationszentrum Karlsruhe, 
Table 1. Crystallographic data for $(\mathrm{RbCl})_{3} \mathrm{Te}(\mathrm{OH})_{6}$.

\begin{tabular}{|c|c|}
\hline$\overline{M_{\mathrm{r}}}$ & 592.41 \\
\hline Crystal system & trigonal \\
\hline Space group & $R \overline{3} c($ no. 167$)$ \\
\hline Wavelength, $\AA$ & 0.71073 \\
\hline Temperature, $\mathrm{K}$ & $150(2)$ \\
\hline \multicolumn{2}{|l|}{ Lattice parameters (hexagonal setting) } \\
\hline$a, \AA$ & $14.4392(8)$ \\
\hline$c, \AA$ & $10.4301(16)$ \\
\hline$V, \AA^{3}$ & $1883.2(3)$ \\
\hline$Z$ & 6 \\
\hline$\rho_{\text {calcd }}, \mathrm{g} \mathrm{cm}^{-3}$ & 3.13 \\
\hline Absorption coefficient, $\mathrm{mm}^{-1}$ & 14.6 \\
\hline $\mathrm{F}(000), \mathrm{e}$ & 1608 \\
\hline Crystal size, $\mathrm{mm}^{3}$ & $0.43 \times 0.34 \times 0.27$ \\
\hline Range, deg & $4.23-25.02$ \\
\hline Index ranges hkl & $-14 \rightarrow 17, \pm 17, \pm 12$ \\
\hline Reflections collected / independent / $\mathrm{R}_{\text {int }}$ & $3371 / 374$ / 0.0839 \\
\hline Completeness to $\theta=25.02^{\circ}$ & $99.7 \%$ \\
\hline Absorption correction & analytical \\
\hline Transmission max. / min. & $0.111 / 0.062$ \\
\hline Data / restraints / ref. parameters & $374 / 1 / 27$ \\
\hline Final $R 1 / w R 2[I \geq 2 \sigma(I)]$ & $0.0282 / 0.0707$ \\
\hline Final $R 1 / w R 2$ (all data) & $0.0293 / 0.0711$ \\
\hline Goodness-of-fit on $\mathrm{F}^{2}$ & 1.227 \\
\hline Extinction coefficient & $0.0027(2)$ \\
\hline Largest diff. peak / hole, e $\AA^{-3}$ & $0.75 /-0.56$ \\
\hline
\end{tabular}

Table 2. Atomic positions and displacement parameters $\left(\AA^{2}\right.$. $\left.10^{3}\right)$ for $(\mathrm{RbCl})_{3} \cdot \mathrm{Te}(\mathrm{OH})_{6}$.

\begin{tabular}{llllll}
\hline \multicolumn{1}{l}{ Atom W. position } & $x$ & $y$ & $z$ & $U_{\text {iso }}{ }^{\text {a }}$ \\
\hline $\mathrm{Te}$ & $6 a$ & 0 & 0 & 0 & $0.0130(3)$ \\
$\mathrm{Rb}$ & $18 e$ & $1 / 3$ & $0.12091(4)$ & $-1 / 12$ & $0.0242(3)$ \\
$\mathrm{Cl}$ & $18 e$ & $1 / 3$ & $-0.09702(12)$ & $-1 / 12$ & $0.0239(5)$ \\
$\mathrm{O}$ & $36 f$ & $0.1191(3)$ & $0.0978(3)$ & $0.0999(3)$ & $0.0186(8)$ \\
$\mathrm{H}$ & $36 f$ & $0.136(5)$ & $0.058(5)$ & $0.161(5)$ & $0.038(18)$ \\
\hline${ }^{\mathrm{a}} U_{\text {iso }}$ & \multicolumn{1}{l}{ is defined as $\exp \left[-8 \pi^{2} U\left(\sin ^{2} \theta / \lambda^{2}\right)\right]}$. & &
\end{tabular}

76344 Eggenstein-Leopoldshafen, Germany (fax: +49-7247808-666; e-mail: crysdata@ fiz-karlsruhe.de, http://www.fizkarlsruhe.de/request_for_deposited_data.html) on quoting the deposition number CSD-423652.

\section{Results and Discussion}

By systematic investigation of mixtures of alkali halides with telluric acid in water we have found a hitherto unknown compound in the system $\mathrm{RbCl}-\mathrm{Te}(\mathrm{OH})_{6}$. The X-ray diffraction investigations have proven that the new compound has the formula $(\mathrm{RbCl})_{3} \cdot \mathrm{Te}(\mathrm{OH})_{6}$. Until now only adducts consisting of alkali halides and telluric acid with the molar ratios $1: 1$ and $2: 1$ are known. Therefore, the newly synthesized $(\mathrm{RbCl})_{3} \cdot \mathrm{Te}(\mathrm{OH})_{6}$ is the first compound with a molar ratio salt to telluric acid of $3: 1$. No water molecules are incorporated in the crystals. As the space group of

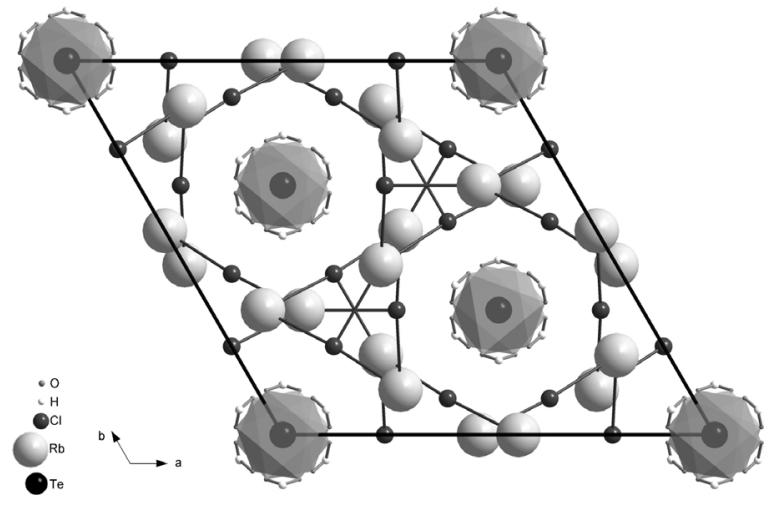

Fig. 1. Crystal structure of $(\mathrm{RbCl})_{3} \cdot \mathrm{Te}(\mathrm{OH})_{6}$ as viewed along [001]. Grey polyhedra: $\mathrm{Te}(\mathrm{OH})_{6}$ octahedra; large white spheres: $\mathrm{Rb}^{+}$; small dark spheres: $\mathrm{Cl}^{-}$.

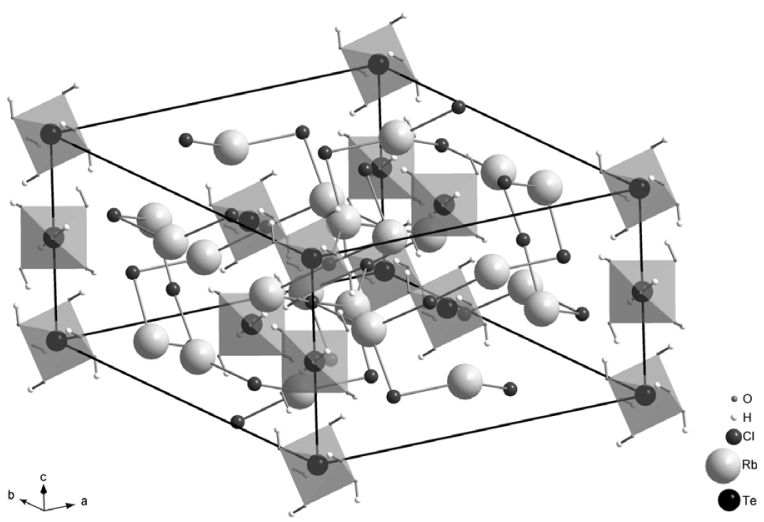

Fig. 2. Crystal structure of $(\mathrm{RbCl})_{3} \cdot \mathrm{Te}(\mathrm{OH})_{6}$; oblique view. Grey polyhedra: $\mathrm{Te}(\mathrm{OH})_{6}$ octahedra; large white spheres: $\mathrm{Rb}^{+}$; small dark spheres: $\mathrm{Cl}^{-}$.

the crystal is centrosymmetric, ferroelectric properties are not expected.

Figs. 1 and 2 show different views of the crystal structure, while Table 3 reports the main interatomic distances and bond angles. The tellurium atoms are located on inversion centers and on the threefold inversion axes, and thus are surrounded by an almost regular octahedron of oxygen atoms with six equal Te-O distances of 1.899(3) $\AA$ and O-Te-O angles of 87.20(14) and $92.80(14)^{\circ}$. These values are comparable to those of the other known adducts of telluric acid with alkali halides, where the Te-O distances vary between 1.90 and $1.92 \AA$ and the $\mathrm{O}-\mathrm{Te}-\mathrm{O}$ angles between 87.1 and $91.6^{\circ}$. The rubidium ion has a ninefold coordination by five chlorine and four oxygen atoms belonging to two different $\mathrm{Te}(\mathrm{OH})_{6}$ groups (Fig. 3). The coordination polyhedra around the $\mathrm{Rb}$ ions form a threedimensional network connected by common edges and 
Table 3. Bond lengths $(\AA)$ and angles $(\mathrm{deg})$ for $(\mathrm{RbCl})_{3}$. $\mathrm{Te}(\mathrm{OH})_{6}$.

\begin{tabular}{lcclll}
\hline $\mathrm{Te}-\mathrm{O}$ & $1.899(3)$ & $6 \times$ & & & \\
$\mathrm{Rb}-\mathrm{O}$ & $2.972(3)$ & $2 \times$ & $\mathrm{Rb}-\mathrm{O}$ & $3.507(4)$ & $2 \times$ \\
$\mathrm{Rb}-\mathrm{Cl}$ & $3.147(2)$ & & $\mathrm{Rb}-\mathrm{Cl}$ & $3.177(1)$ & $2 \times$ \\
$\mathrm{Rb}-\mathrm{Cl}$ & $3.828(1)$ & $2 \times$ & $\mathrm{O}-\mathrm{Cl}$ & $3.114(4)$ & \\
$\mathrm{O}-\mathrm{Te}-\mathrm{O}$ & $87.20(14)$ & $6 \times$ & $\mathrm{O}-\mathrm{Te}-\mathrm{O}$ & $92.80(14)$ & $6 \times$ \\
$\mathrm{O}-\mathrm{Te}-\mathrm{O}$ & 180.0 & $3 \times$ & & & \\
\hline
\end{tabular}

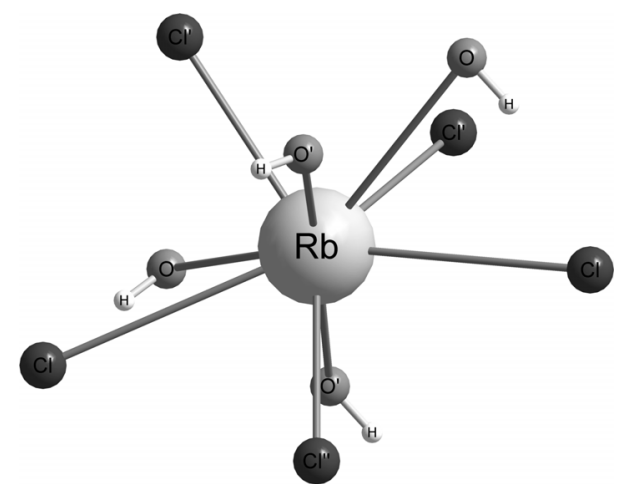

Fig. 3. Coordination polyhedron around the rubidium ion. $\mathrm{Rb}^{+}$is surrounded by five chlorine and four oxygen atoms forming an irregular tricapped trigonal prism.

faces. The $\mathrm{Te}(\mathrm{OH})_{6}$ octahedra and $\mathrm{RbCl}_{5} \mathrm{O}_{4}$ polyhedra form a three-dimensional network which is additionally stabilized by hydrogen bonds.

All hydrogen atoms of the $\mathrm{Te}(\mathrm{OH})_{6}$ groups are involved in hydrogen bonds of the $\mathrm{O}-\mathrm{H} \cdots \mathrm{Cl}$ type, connecting six different chlorine atoms with a mean Cl-O distance of 3.114(4) $\AA$ (Fig. 4). This is slightly smaller than the $\mathrm{Cl}-\mathrm{O}$ distance $3.146 \AA$ found in $(\mathrm{CsCl})_{2} \cdot \mathrm{Te}(\mathrm{OH})_{6}$ [4]. Each chlorine atom is connected by hydrogen bonds to two oxygen atoms belonging

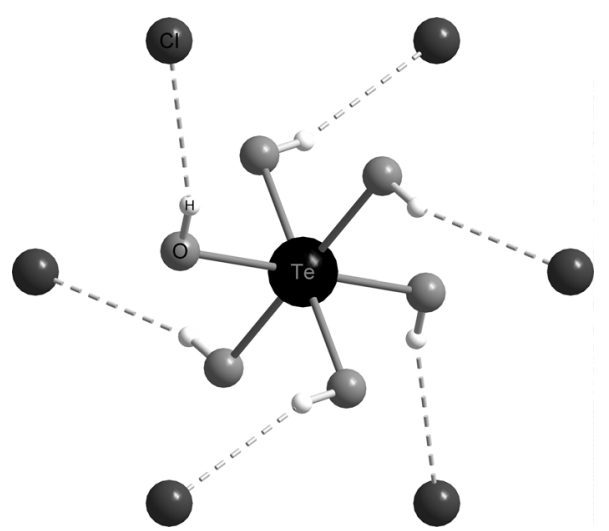

Fig. 4. View of the $\mathrm{Te}(\mathrm{OH})_{6}$ octahedron; all hydrogen atoms are involved in hydrogen bonds to six different chlorine atoms; view along [001].

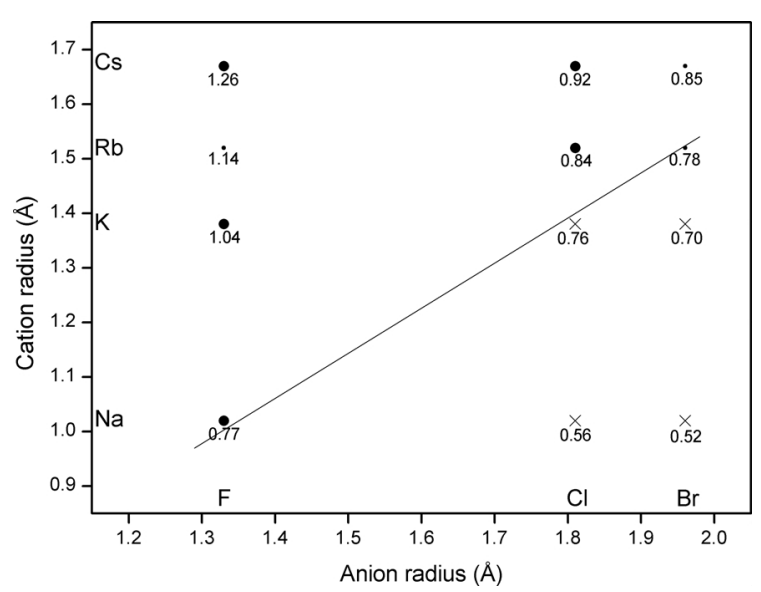

Fig. 5. Ionic radii of alkali metal cations versus ionic radii of halide anions. Ionic radii (six-fold coordination) according to Shannon [7]. Crosses: non-existing; larger dots: existing; small dots: unknown. Numbers under symbols give the ratio of the ionic radii of the alkali metal and the halogen.

to different $\mathrm{Te}(\mathrm{OH})_{6}$ groups. These $\mathrm{O}-\mathrm{H} \cdots \mathrm{Cl}$ hydrogen bonds support the formation of chains along the $c$ axis. There are no direct hydrogen bonds between $\mathrm{Te}(\mathrm{OH})_{6}$ groups. In $(\mathrm{CsCl})_{2} \cdot \mathrm{Te}(\mathrm{OH})_{6}$ all $\mathrm{OH}$ groups of the $\mathrm{Te}(\mathrm{OH})_{6}$ octahedron are also involved in hydrogen bonds, but the chlorine atom is the acceptor for three hydrogen bonds, and the hydrogen bonds form a three-dimensional network. This is possible because of the $2: 1$ ratio of halide to telluric acid in $(\mathrm{CsCl})_{2} \cdot \mathrm{Te}(\mathrm{OH})_{6}$. The $\mathrm{O}-\mathrm{H} \cdots \mathrm{F}$ bonds in $(\mathrm{KF})_{2} \cdot \mathrm{Te}(\mathrm{OH})_{6}$ [2] show a similar arrangement as the $\mathrm{O}-\mathrm{H} \cdots \mathrm{Cl}$ bonds in $(\mathrm{CsCl})_{2} \cdot \mathrm{Te}(\mathrm{OH})_{6}$ due to the same atomic ratio. In contrast, in $\mathrm{NaF} \cdot \mathrm{Te}(\mathrm{OH})_{6}[1]$ and $(\mathrm{CsF})_{2} \cdot \mathrm{Te}(\mathrm{OH})_{6} \cdot\left(\mathrm{H}_{2} \mathrm{O}\right)_{2}$ [3] not only $\mathrm{O}-\mathrm{H} \cdots \mathrm{F}$ bonds are found but also $\mathrm{O}-\mathrm{H} \cdots \mathrm{O}$ bonds. In both compounds the hydrogen bonds lead to the formation of a threedimensional arrangement.

The question arises why telluric acid obviously does not form adducts with the chlorides and bromides of sodium, potassium, and ammonium. From the abovepresented discussion it seems to be evident that hydrogen bonds are important for the stabilization of the crystal structure of telluric acid adducts. Both chloride and bromide anions may act as hydrogen bond acceptors. Therefore geometric reasons may be responsible. We assume that the formation of a telluric acid alkali halide adduct is controlled by the ratio between the radii of the cations and the anions in the halide. A stable adduct is obtained when the halide involved consists of a relatively large cation and a relatively 
small anion (Fig. 5). Only from halides with a radius ratio cation to anion $\geq 0.77$ stable adducts have been found. Below that ratio, telluric acid and alkali halides crystallized separately (ionic radii according to Shan- non [7]). Further investigations will be necessary to confirm this assumption. It is not known yet if RbF, $\mathrm{NH}_{4} \mathrm{~F}, \mathrm{RbBr}$, and $\mathrm{CsBr}$ form adducts with telluric acid or not.
[1] R. Allmann, Acta Crystallogr. 1976, B32, 1025 - 1028.

[2] R. Allmann, W. Haase, Inorg. Chem. 1976, 15, $804-$ 807.

[3] R. Allmann, J. Rius, Acta Crystallogr. 1978, A34 suppl., 167.

[4] M. T. Averbuch-Pouchot, Z. Kristallogr. 1988, 182, $291-295$.

[5] CRYsAlis CCD and CRYsAlis ReD, (version
1.171.32.24), Oxford Diffraction Ltd., Abingdon, Oxford (U.K.) 2008.

[6] G. M. Sheldrick, SHELXs/L-97, Programs for Crystal Structure Determination, University of Göttingen, Göttingen (Germany) 1997. See also: G. M. Sheldrick, Acta Crystallogr. 1990, A46, 467-473; ibid. 2008, A64, $112-122$.

[7] R. D. Shannon, Acta Crystallogr. 1976, A32, 751 - 767. 